\title{
Welding of high-entropy alloys and compositionally complex alloys-an overview
}

\author{
Michael Rhode ${ }^{1,2}$ (D) $\cdot$ Tim Richter $^{1} \cdot$ Dirk Schroepfer $^{1} \cdot$ Anna Maria Manzoni $^{3} \cdot$ Mike Schneider $^{4} \cdot$ Guillaume Laplanche $^{4}$
}

Received: 17 November 2020 / Accepted: 11 March 2021 / Published online: 14 April 2021

(C) The Author(s) 2021

\begin{abstract}
High-entropy alloys (HEAs) and compositionally complex alloys (CCAs) represent new classes of materials containing five or more alloying elements (concentration of each element ranging from 5 to 35 at. \%). In the present study, HEAs are defined as single-phase solid solutions; CCAs contain at least two phases. The alloy concept of HEAs/CCAs is fundamentally different from most conventional alloys and promises interesting properties for industrial applications (e.g., to overcome the strength-ductility trade-off). To date, little attention has been paid to the weldability of HEAs/CCAs encompassing effects on the welding metallurgy. It remains open whether welding of HEAs/CCAs may lead to the formation of brittle intermetallics and promote elemental segregation at crystalline defects. The effect on the weld joint properties (strength, corrosion resistance) must be investigated. The weld metal and heat-affected zone in conventional alloys are characterized by non-equilibrium microstructural evolutions that most probably occur in HEAs/CCAs. The corresponding weldability has not yet been studied in detail in the literature, and the existing information is not documented in a comprehensive way. Therefore, this study summarizes the most important results on the welding of HEAs/CCAs and their weld joint properties, classified by HEA/CCA type (focused on $\mathrm{CoCrFeMnNi}$ and $\mathrm{Al}_{\mathrm{x}} \mathrm{CoCrCu}_{\mathrm{y}} \mathrm{FeNi}$ system) and welding process.
\end{abstract}

Keywords Welding $\cdot$ High-alloyed $\cdot$ Innovative materials $\cdot$ Cracking

Recommended for publication by Commission II - Arc Welding and Filler Metals

Michael Rhode

michael.rhode@bam.de

1 Department 9 - Component Safety, Bundesanstalt für Materialforschung und -prüfung (BAM), Unter den Eichen 87, 12205 Berlin, Germany

2 Institute for Materials Science and Joining Technology, Otto-von-Guericke-University Magdeburg, Universitätsplatz 2, 39106 Magdeburg, Germany

3 Department 5 - Materials Engineering, Bundesanstalt für Materialforschung und -prüfung (BAM), Unter den Eichen 87, 12205 Berlin, Germany

4 Institut für Werkstoffe, Ruhr-Universität Bochum, Universitätsstr. 150, 44801 Bochum, Germany

\section{Introduction}

\subsection{A new class of materials}

High-entropy alloys (HEAs) represent a new class of materials [1-3]. They usually contain more than five alloying elements and are defined in this overview as single-phase solid solutions. The possible concentrations for each element are within 5 and 35 at.\%. The HEA concept is fundamentally different from that of most conventional alloys that are used in the manufacturing of components today.

For instance, traditional alloys resulted from metallurgical "trial and error" and consist of one principal element to which small quantities of alloying elements are added to improve targeted properties. For example, $\mathrm{Cr}$ is added to the base element $\mathrm{Fe}$ in steels or Ni-base superalloys to improve strength and corrosion resistance. $\mathrm{Cu}$ is alloyed to the base element $\mathrm{Al}$, or $\mathrm{Al}$ is added to Ti-base lightweight materials to improve strength. Each of these alloys offers typical properties such as high mechanical strength and ductility, accompanied by a high specific weight for steels [4] that are of prime importance 
for structural applications. As another example, due to their high strength-to-weight ratio, Al- and Ti-alloys allowed the development of the modern aircraft industry [5]. However, it is not always possible to improve all the properties (mechanical strength, ductility, specific alloy weight, creep, corrosion resistance, and so on) with traditional alloying concepts, and a compromise has to be found.

HEAs have the potential to overcome the mismatch between desired and currently available material properties $[1-3,6]$. In addition, the terms medium entropy alloy (MEA) and compositionally complex alloy (CCA) can be found in literature and will be defined in Sect. 1.4. Figure 1 shows the general strength-ductility trade-off, i.e., highstrength alloys have usually poor ductility and vice versa. However, several HEAs allow overcoming the strengthductility trade-off due to their multiple principal element composition. These include superior mechanical properties like specific strength [1, 2, 9-11], mechanical performance at high temperature [12-14], (shown in Fig. 2), or superior fracture toughness at cryogenic temperature $[15,16]$. Other alloy concepts provide special properties like superparamagnetism [17].

\subsection{Debated core effects of HEAs}

The multi-element character of HEAs leads to some particular effects that were strongly debated in the literature during the last two decades. Following Refs. [1, 2, 18], four core effects were proposed in the early stages of HEA research:

1. High-entropy effect

2. Lattice distortion effect

3. Sluggish diffusion

Fig. 1 Mechanical properties at room temperature of selected HEAs (in green), metastable MEAs (blue), and CCAs (orange) vs. constructional and industrially applied steel grades, $\mathrm{Al}-$ and $\mathrm{Mg}$ alloys, derived from and in accordance with [6-10]

\section{Cocktail effect}

The high (configurational) entropy effect was initially claimed to be the dominating factor for stabilizing a solid solution compared to other factors like atomic radii and packing density [19] (Hume-Rothery rules). The lattice distortion effect was assumed to be caused by various elements forming the crystal lattice with different atomic radii, which impose local displacements of the atoms compared to their positions in diluted alloys. This was thought to result in enhanced solid solution hardening compared to conventional alloys. Systematic studies of lattice distortion are rare (like in [20]) and may not apply to all HEA compositions. The sluggish diffusion effect [21, 22] assumes that high-temperature diffusion and diffusion-controlled phenomena such as oxidation [13], creep [20], phase transformations [23], and growth of particles [24] are slower in HEAs compared to conventional alloys since vacancies may be surrounded by various atomic configurations. These fluctuations induce an increase of the activation energy for diffusion and thus slow down diffusion kinetics. Only a few diffusion experiments have been performed so far and several studies debated the sluggish diffusion effect $[1,18]$. The cocktail effect reflects the idea that a property of the alloy such as its hardness can exceed the weightaveraged hardness of its pure elements. However, this effect is not a real hypothesis but rather the idea that unique HEA properties are the result of combinations of chemical elements that were not considered in materials science before. In the materials science community, it is widely accepted that these four core effects are not fully applicable or simply do not explain what is observed in experiments.

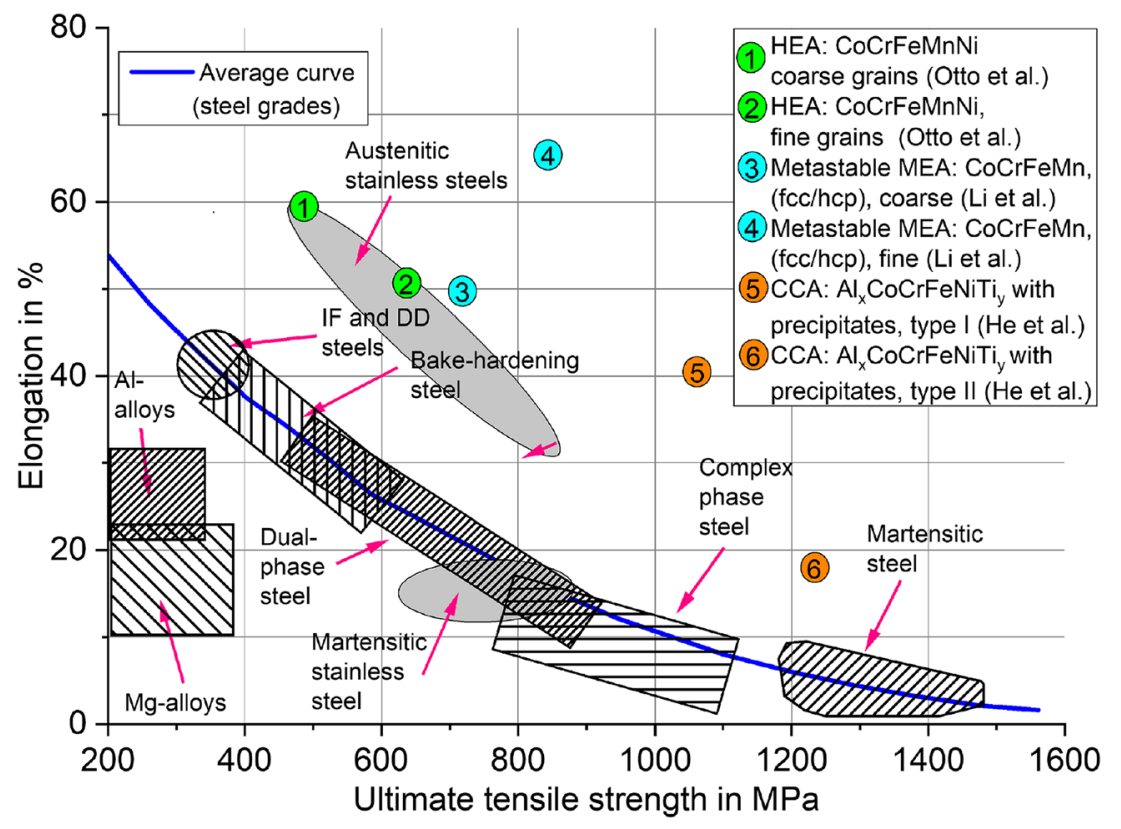


Fig. 2 High-temperature yield strength of refractory HEA and MEA compared to conventional creep-resistant Ni-base alloys, in accordance with $[9,20]$ (note: the $\mathrm{NbMoTaW}$ system was originally referred to in the reference as HEA, we used MEA due to the 4element system)

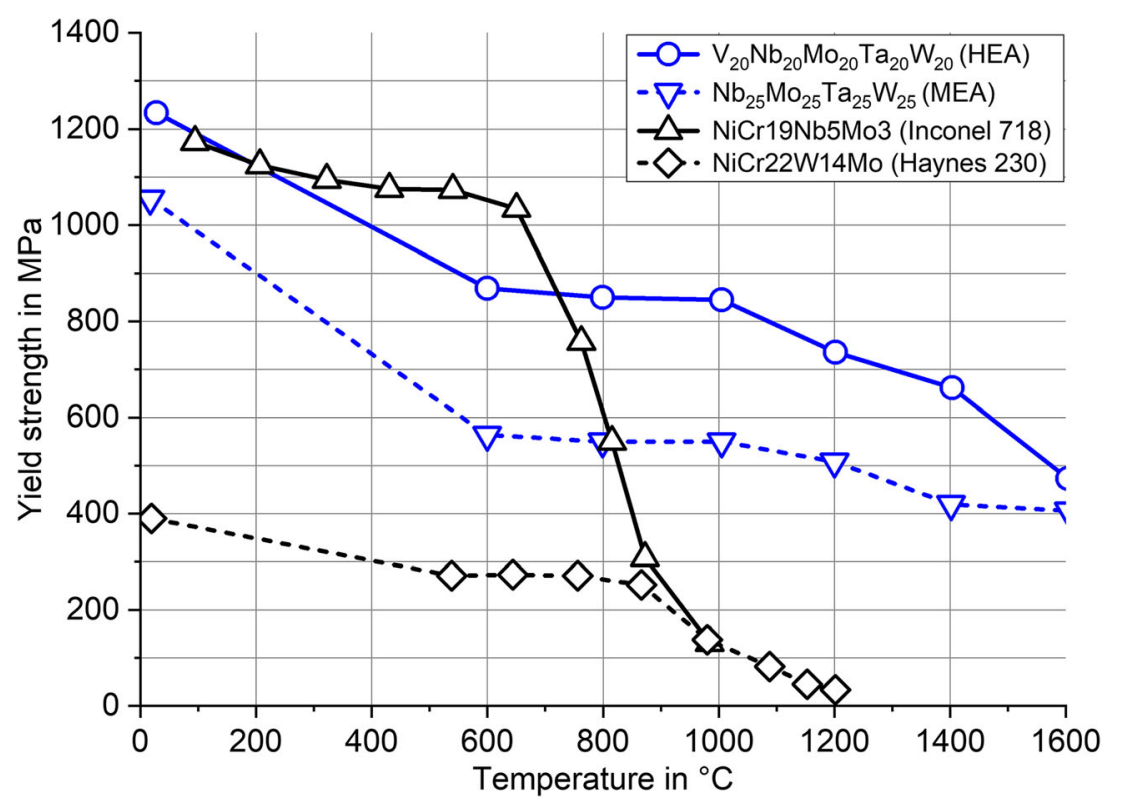

\subsection{Challenges for welding processing}

The major part of the studies on HEAs has been aimed at providing a fundamental understanding of composition and microstructure and their influences on real vs. predicted properties [25, 26-28]. Recently, the focus has become more application-oriented to develop HEAs that have tailored properties. For that purpose, candidate systems were identified, cast, and/or processed and their real microstructures investigated [1]. This promises HEAs for industrial applications with outstanding properties that overcome "issues" of conventional alloys like the strength-ductility trade-off. Figure 1 shows the mechanical properties of different steels vs. available HEAs, MEAs, and CCAs (see definitions in Sect. 1.4). Figure 2 highlights the superior high-temperature mechanical properties of selected refractory HEAs compared to conventional Ni-base alloys.

In the context of component fabrication, welding is one of the main manufacturing processes. The successful and reliable use of new materials depends on their weldability and if they can generally be joined. For that reason, fundamental testing of weldability becomes a key challenge for HEAs in engineering applications.

The quality of a weld joint depends on the microstructure of the different welding zones, their corresponding (mechanical) properties, and the structural integrity of the welded joint $[29,30]$. The welding process influences the material behavior and properties regarding the differences in energy input and the maximum temperature (e.g., melting and cooling). As a result, the structure and properties of the welded joints are affected, e.g., the size/shape of the weld pool and the heat-affected zone (HAZ), the hardness distribution-expressed by hardening or softening, residual stresses, defects, and weld imperfections.

To date, little attention has been paid to the weldability of HEAs. First summarized investigations can be found in refs. [31-34]. These studies, however, do not encompass the systematic investigation of the underlying welding metallurgy and its influence on the desired properties. It is still unclear whether fusion welding of HEAs causes undesired effects like the formation of intermetallic compounds (IMCs), segregation of specific elements at crystalline defects, and/or unexpected deteriorations of the weld joint properties in terms of strength and/or corrosion resistance.

The already existing information on HEAs and welding is fragmented with either a focus on the welding process, its influence on the weld joint properties, or the investigated HEA material. However, these studies could only partially consider the properties of weld joints required in applications. A comprehensive database of HEA weldability is currently missing. The scope of this study is, therefore, to summarize the available studies on welding of HEAs with respect to the HEA type, the applied welding process, and its influence on the weld joint properties.

\subsection{HEA types}

As previously mentioned, HEAs are defined in this overview as single-phase and disordered solid solutions that contain at least five elements in near equiatomic proportions while so-called medium-entropy alloys (MEAs) consist of three to four main elements. The definition of HEAs has evolved over time as a result of intensive research and abuse of language appeared in the literature, namely, multi-phase alloys and even compositionally 
complex IMCs were occasionally referred to as HEAs. During the setup of the priority program on HEAs in Germany by the German Research Foundation (DFG), the international committee members have introduced the term compositionally complex alloys (CCAs) to avoid confusion between different terms used in the literature. Since then, CCAs are defined as alloys that contain at least two phases (ordered and/or disordered) and have compositions within the same limits as HEAs (5 to 35 at.\%, see Sect. 1) [11] while HEAs are single-phase and disordered solid solutions [3, 32, 33].

In recent years, an increasing number of HEAs/CCAs were introduced and Miracle and Senkov listed 375 different HEA/CCA types in their review article from 2016 [1]. They proposed a classification system for HEAs, which is given in Table 1 (extract of the most common families). Different designation systems can be found. HEAs/CCAs are typically designated by their chemical elements in alphabetical order, e.g., CoCrFeMnNi, or following the order of the elements in the periodic table, i.e., $\mathrm{CrMnFeCoNi}$. The designation of varying compositions can also be found, e.g., in $\mathrm{Al}_{x} \mathrm{CoCrCu}_{y} \mathrm{FeNi}$ where the proportions of $\mathrm{Co}, \mathrm{Cr}, \mathrm{Fe}$, and $\mathrm{Ni}$ are equal and molar, while the $\mathrm{Al}$ and $\mathrm{Cu}$ concentrations vary and are symbolized by " $x$ " and " $y$." In the following, the alphabetical order is used to name HEAs, MEAs, and CCAs.

From the welding processing point of view, not all currently investigated HEAs/CCAs will be suitable for components as they encompass very expensive metals (like rare earth metals and precious metals). Hence, their further application for (welded) components is at least questionable, and it is challenging to classify possible HEA/CCA systems in view of their weldability. We thus sorted available studies on welding of HEAs/CCAs by welding processes. In addition, we aim to give an overview of what challenges are anticipated with the current and future weld fabrication of these novel materials. Many HEAs/CCAs show a way more complex metallurgical behavior than expected, which is expressed by the formation of secondary phases such as IMCs during welding.

Table 1 Classification of (the most common) HEAs vs. chemical composition [1]

\begin{tabular}{ll}
\hline HEA system & Possible elements \\
\hline Refractory metal & $\mathrm{Hf}, \mathrm{Mo}, \mathrm{Nb}, \mathrm{Ta}, \mathrm{W}, \mathrm{Zr}$, \\
3d transition metal & $\mathrm{Co}, \mathrm{Cr}, \mathrm{Cu}, \mathrm{Fe}, \mathrm{Mn}, \mathrm{Ni}, \mathrm{Zn}, \mathrm{Zr}$ \\
Light metal & $\mathrm{Al}, \mathrm{Be}, \mathrm{Li}, \mathrm{Mg}, \mathrm{Sc}, \mathrm{Ti}$ \\
Precious metal & $\mathrm{Ag}, \mathrm{Au}, \mathrm{Ir}, \mathrm{Pd}, \mathrm{Pt}, \mathrm{Rh}, \mathrm{Ru}$ \\
\hline
\end{tabular}

\section{Welding processing, challenges, and perspectives of welded HEA joints}

For the last 5 years, a continuously increasing number of scientific studies was published that contain the terms "welding" and "high-entropy alloys" [31-34]. In these recent studies, welding of $3 \mathrm{~d}$-transition-metal HEAs/CCAs was primarily investigated. The focus of HEA/CCA welding so far is on different welding processes including:

- Fusion welding like tungsten inert gas (TIG) welding with low energy density (and high heat input), laser beam welding (LB/LBW), and electron beam welding (EB/ EBW) with high energy density (but low heat input).

- Solid-phase processes such as friction stir welding (FSW). In this case, heat generation by friction is used to generate temperatures of approximately $80 \%$ of the liquidus temperature.

There are further studies on welding of HEAs/CCAs by special processes such as explosion welding [35], diffusion welding [36], and individual examinations on refractory HEAs [37]. These investigations will not be discussed in the following, as this overview focuses on basic welding properties of the equiatomic CoCrFeMnNi HEA ("Cantor" alloy in accordance with [6]) and various compositions of the $\mathrm{Al}_{x} \mathrm{CoCrCu}_{y} \mathrm{FeNi}$ (with $0 \leq x \leq 1$ and $0 \leq y \leq 1$ ) HEAs/ CCAs [38-40].

\subsection{General aspects of welding of HEAs}

It has been reported that welding defects in the face-centered cubic (fcc) CoCrFeMnNi HEA such as (hot) cracks or pores can be mostly avoided by welding parameter adjustments [41, 42]. Nonetheless, it should be noted that these investigations have only involved remelted base material (BM) or singlelayer butt joints. Neither multi-layer welds nor complex joint geometries were investigated so far. Weldability studies, which contain data on filler metals for welding of HEAs or use them as filler metals, are rare. Publications on brazing/ soldering [43] or fusion welding [44] can be found but are out of the scope of the present overview. The problem is that the nearly equiatomic composition must be guaranteed. It must be clarified how a certain HEA/CCA-system must be processed (e.g., manufacturing of rods, wires, etc.). Further effects like the possible burn-off loss of chemical elements must be identified and compensated by the filler metal. It can be concluded that only a rudimentary weldability could be proven for the $\mathrm{CoCrFeMnNi}$ alloy.

$\mathrm{Wu}$ et al. [45] published a study on EB-welded $\mathrm{CoCrFeMnNi}$ (see Fig. 3). Neither solidification nor liquation cracking was reported for the weld joint, which is probably related to the narrow solidification range $\left(\sim 60^{\circ} \mathrm{C}\right.$ [46]) of this 
a

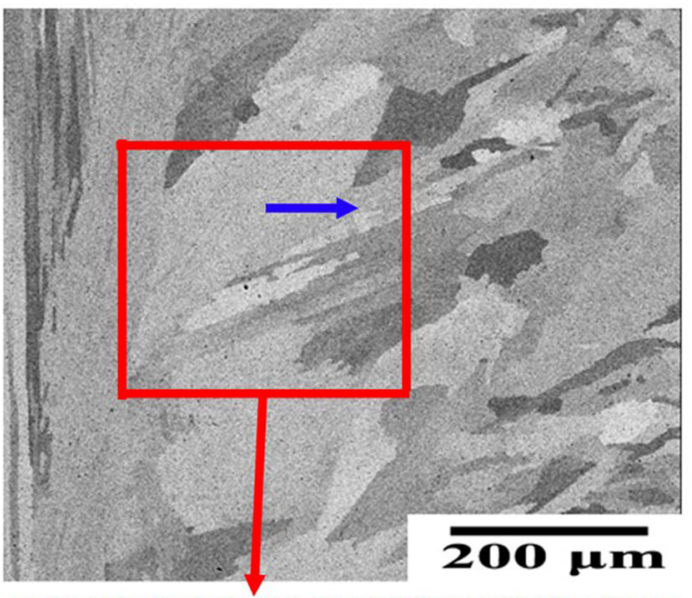

b

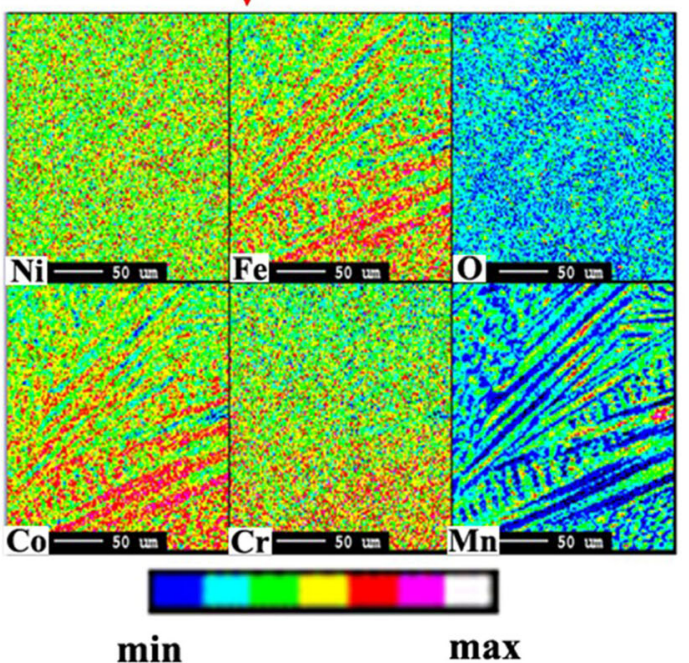

C

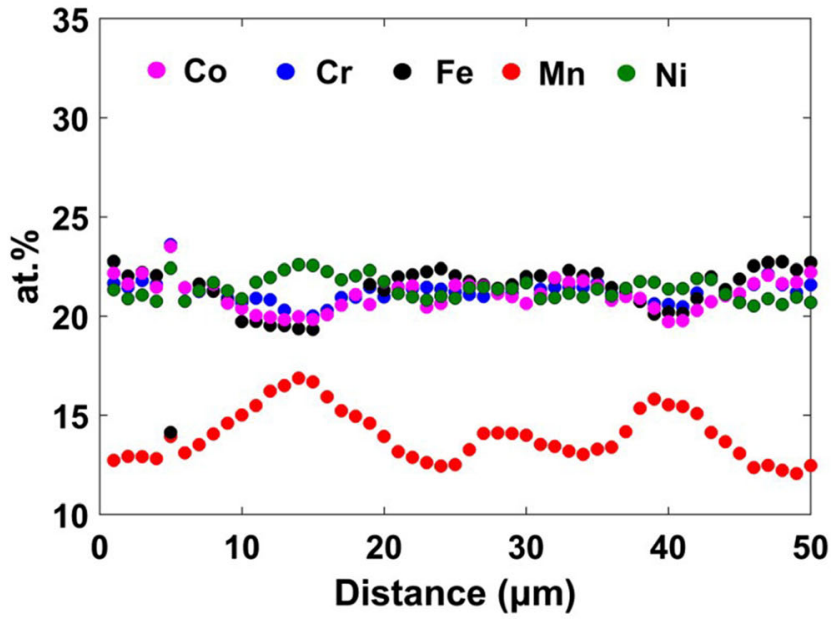

Fig. 3 EB welded CoCrFeMnNi WM. a BSE micrograph showing epitaxial grain growth. b Elemental maps from the framed area in (a). c Mn concentration profile showing maxima in the interdendritic regions and minima within the dendritic cores. The figures were taken from ref. [45], reprinted by permission of Informa UK Limited, trading as Taylor \& Francis Group

alloy. The authors suggested that the CoCrFeMnNi alloy shows promising weldability for fusion welding techniques.
Further studies confirmed the good weldability in terms of defect-free welded joints as one of the main goals for weld processing, e.g., without further preheating for a wide range of welding processes including LBW and TIG [41, 42, 45, 47-49]. All these studies show the well-known epitaxial (and partially excessive) grain growth from the fusion line toward the centerline of the weld joint during dendritic solidification (see Fig. 3a). This behavior is a result of the applied heat input during welding, i.e., the welding parameters that influence the weld pool shape. According to ref. [45], the EB and TIG WM of the CoCrFeMnNi showed dendritic solidification with dendritic cores enriched in $\mathrm{Co}, \mathrm{Cr}$, and $\mathrm{Fe}$ and interdendritic regions rich in Ni and Mn (see Fig. 3b). This elemental micro-segregation can perhaps influence the hotcracking behavior of the CoCrFeMnNi HEA, but this has not been investigated so far.

At high energy densities (as provided by LBW and EBW), the $\mathrm{Mn}$ content in the weld metal decreased to an average value of $\sim 15$ at.\% (see Fig. 3c), which is a result of Mn vaporization due to its high vapor pressure (visually recognizable by so-called "welding plume") $[42,45,50]$. The consequences of this $\mathrm{Mn}$ loss on properties like corrosion and wear resistance cannot yet be foreseen, and it is, therefore, unclear whether the integrity of the welded CoCrFeMnNi HEA can be guaranteed for structural applications requiring welding.

Considering that the $\mathrm{CoCrFeMnNi}$ alloy is one of 375 HEA/CCA-types (in accordance with [1]), a high number of welding experiments must be investigated to identify HEA/ CCA suitability for welding processing. This does not imply that each of the numerous HEA/CCA-types has a unique weldability, i.e., materials within a certain range of chemical compositions can have similar welding properties. A targeted approach focused on the desired material properties and its specifications (e.g., corrosion resistance) and including additional boundary conditions (i.e., costs, material availability, etc.) would be helpful to limit the number of alloy systems and welding processes.

\subsection{Welding influence on joint properties}

\subsubsection{Mechanical properties}

The influence of different welding processes on the mechanical properties of the CoCrFeMnNi HEA is summarized in Fig. 4 . The average values for the yield strength $\left(R_{\mathrm{p} 0.2}\right)$, the tensile strength $\left(R_{\mathrm{m}}\right)$, the elongation to fracture $(\varepsilon)$, and the hardness of the BM are compared to those of the WM for different welding processes: TIG and LBW (FSW will be discussed later), $R_{m}$ and $\varepsilon$ are reduced in the welded condition compared to the base material while the hardness increases. This corresponds to a decreased mechanical performance that is mostly reflected by the reduction of the ductility and probably the toughness of the WM, i.e., decreased resistance to 
Fig. 4 Mean values and corresponding error bars of the yield stress at $0.2 \%$ plastic strain $\left(R_{\mathrm{p} 0.2}\right)$, the ultimate tensile stress $\left(R_{m}\right)$, elongation to fracture $(\varepsilon)$, and hardness (HV0.1 to HV0.5) of the equiatomic $\mathrm{CoCrFeMnNi}$ $\mathrm{BM}$ and $\mathrm{WM}$ for different welding processes: TIG: $[45,48$, 52], FSW: [47, 53, 54], LB: [41, $42,45,49,50,55]$

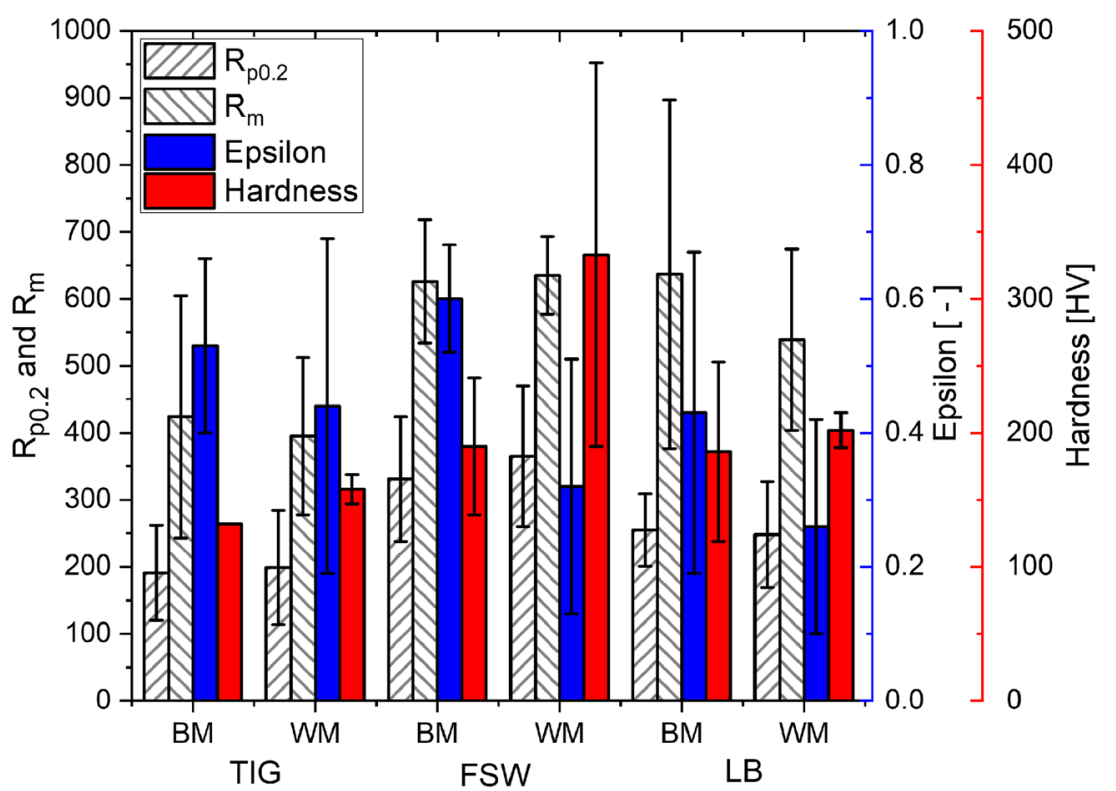

crack-growth compared to the BM. In this respect, the occurring welding residual stresses vs. the used weld heat input are important and should be investigated in future studies. The degradation of the mechanical properties in welded joints compared to the BM was attributed by $\mathrm{Wu}$ et al. [45] to a change of grain size and elemental segregation in the WM.

\subsubsection{Weld heat input effect}

For the TIG process, it is not yet possible to conclude on an influence of the welding parameters on HEA welded joints. LBW was reported for different weld heat inputs for the CoCrFeMnNi HEA [42, 47]. Nam et al. [42] showed results for LBW for a $1.5 \mathrm{~mm}$ sheet with varying heat inputs between 0.21 and $0.35 \mathrm{~kJ} / \mathrm{cm}$ (note: calculated from the laser power $3.5 \mathrm{~kW}$ and welding speed from 6 to $10 \mathrm{~m} / \mathrm{min}$ as the authors did not refer to the heat input). This welding parameter window led to a far too low heat input and resulted in partial and insufficient welding penetration. In addition, a large heat input $(0.35 \mathrm{~kJ} / \mathrm{cm}$ from [42]) resulted in a so-called "undercut" phenomenon due to the evaporation of elements with high vapor pressures like Mn [51]. This is similar to the burn-off loss of filler metals. For all the heat inputs that were investigated, shrinkage voids were found to form, and the origin was not discussed, but it is obvious that the evaporation of $\mathrm{Mn}$ had an influence.

At the current state of the art, no general influence of the welding parameters on the mechanical properties (described in Fig. 4) of the welded joints can be derived from the mentioned publications. To restore the mechanical properties in the weld joint, depending on the alloy composition and welding process, a post-weld heat treatment (PWHT) might be required and is not exclusively related to precipitation- hardened materials (like Ni-base superalloys [56]). Despite the metallurgical changes by a PWHT, a further relaxation of the welding residual stresses is a considerable reason for conducting such procedure. In the case of HEAs, the number of published studies on this aspect is limited. Currently, no general recommendation is possible if PWHT is "mandatory/ optional."

Nam et al. [41] showed a degradation of the mechanical properties of LBW joints of CoCrFeMnNi HEA sheets (coldrolled prior to welding). The authors attributed this degradation to the recrystallization of the grains and (probably) the "disappearance of conglomerated dislocations" through the welding heat input in the as-welded condition. A PWHT between 800 and $1000{ }^{\circ} \mathrm{C}$ positively influenced the ductility compared to the as-welded condition. In the annealed condition, the strength and ductility of the HEA BM and WM were similar for each respective PWHT-condition, although it was accompanied by a significant loss of the tensile strength compared to the initial condition (BM: cold-rolled, WM: "as-LBwelded").

Consequently, further research should focus on the identification of possible PWHT effects in HEAs/CCAs to optimize the properties of weld joints. As mentioned previously, studies on welding of HEAs were limited to re-melted materials or single-layer butt joints. (Filler materials not commercially available). For that reason, there is no knowledge of the multi-layer welding behavior of HEAs/CCAs so far.

\subsubsection{Thermophysical properties vs. welding}

Currently, only a limited number of studies are available for basic thermophysical properties of HEAs/CCAs (see Table 2), which will be important for the welding of components in 
Table 2 Thermophysical properties at room temperature of HEAs and CCAs [36, 57-62] compared to conv. steels with fcc (316L) [64] and bcc (S235) [63] structures

\begin{tabular}{lllll}
\hline Material & $\mathrm{\kappa}$ in W/mK & $\alpha$ in $10^{-6} 1 / \mathrm{K}$ & $c_{\mathrm{p}}$ in J/kg*K & $T_{\mathrm{s}}$ In ${ }^{\circ} \mathrm{C}$ \\
\hline $\mathrm{CoCrFeMnNi} / H E A$ & $5.6[62]$ & $15.0[57]$ & $450[36]$ & $1289[58]$ \\
$\mathrm{Al}_{0,5}-\mathrm{CoCrFeNi} / C C A$ & $10.5[59]$ & $9.2[60]$ & - & $1358[60]$ \\
$\mathrm{A} 1 \mathrm{CoCrFeNi} / \mathrm{CCA}$ & $11.0[60]$ & $9.0[60]$ & - & $1376[61]$ \\
316L [64]/Austenitic steel & 15.0 & 16.0 & 500 & 1440 \\
$\mathrm{~S} 235[63] /$ Ferritic steel & $40-60$ & 11.0 & 461 & 1460 \\
\hline
\end{tabular}

terms of the calculation of cooling times, weld distortion effects, or suitable weld heat input calculation for multi-layer welding. The CoCrFeMnNi alloy has a relatively low thermal conductivity [62], i.e., about one-third of high-alloyed austenitic steels [64], but it has a comparable heat capacity [35] to that of ferritic and austenitic steels [63, 64]. Table 2 shows the thermophysical properties of the CoCrFeMnNi HEA and two different $\mathrm{Al}_{x} \mathrm{CoCrFeNi} \mathrm{CCAs}$, i.e., thermal conductivity $\mathrm{\kappa}$, thermal expansion coefficient $\alpha$, specific heat capacity $c_{p}$, and melting temperature $T_{s}$. Due to the relatively low thermal conductivity of HEAs/CCAs $(\kappa<11 \mathrm{~W} / \mathrm{mK}$; see Table 2$)$, welding may become problematic as heat accumulates in the welding zone. This could result in severe overheating of the small HAZ with a very high temperature gradient between the weld and the base material. For instance, it is known that brittle IMCs such as the $\sigma$ phase form in the equiatomic CoCrFeMnNi HEA [23, 24] and the equiatomic AlCoCrFeNi CCA [62] when these alloys are subjected to high temperatures (e.g., between 600 and $800{ }^{\circ} \mathrm{C}$ ) for long times. The precipitation of the $\sigma$ phase was reported to increase the hardness and embrittle HEAs and CCAs.

Based on recent phase stability and precipitation kinetics studies [23, 24, 65], it is expected that overheating during welding may lead to the precipitation of IMCs that strongly affect the HAZ-properties of the CoCrFeMnNi HEA and $\mathrm{AlCoCrFeNi}$ CCA. The precipitation of the $\sigma$ phase may reduce the toughness and ductility of the HAZ. If these IMCs are present in the HAZ after welding, a further PWHT may be performed to dissolve these IMCs followed by rapid cooling to freeze the high-temperature microstructure. However, further welding studies are still needed to investigate these possibilities.

From a general viewpoint, the weld shrinks upon cooling, due to thermal contraction, at a much faster rate than the base material. This leads to the formation of high tensile residual stresses in the weld while compression residual stresses develop in the base material. However, the final distribution of the welding residual stresses may be more complex and depends on other factors such as composition, microstructure, possible phase transformations, thermal and mechanical properties, weld seam geometry, and preparation of the welding edge, i.e., the residual stress state prior to welding due to the component processing and restraints due to external fixtures and component stiffness, according to ref. [66]. The tensile residual stresses in the weld seam promote crack formation and propagation and thus lead to a degradation of the component integrity $[67,68]$. Therefore, the design of new HEAs/CCAs with optimized properties for welding should aim at increasing their thermal conductivity to minimize residual stresses and thus reduce their susceptibility to cracking.

\subsection{Current challenges for welding}

\subsubsection{Weld imperfections by fusion welding}

Our investigations and the studies reported in Refs. [42, 45, 50] showed that the formation of pores in the weld joint of the CoCrMnFeNi HEA can be problematic. Figure 5 shows an LB-welded sample on a 2 -mm-thick disc-shaped $(\varnothing=16 \mathrm{~mm})$ CoCrFeMnNi HEA, welded with an IPG YLR-20000 fiber laser using a beam power of $1.2 \mathrm{~kW}$, a focus spot size of 0.2 $\mathrm{mm}$, and a $1 \mathrm{~m} / \mathrm{min}$ welding speed (corresponding to a weld heat input of $0.60 \mathrm{~kJ} / \mathrm{cm}$ ). At present and considering the results of ref. [42, 47], it is assumed that the pores shown in Fig. 5 might be suppressed, or their volume fraction minimized, by adjusting the welding parameters as their presence is related to the chemistry of the CoCrFeMnNi HEA.

Indeed, these pores may result from the evaporation of $\mathrm{Mn}$ since LBW and EBW are high-power processes [42, 45, 50]. Keyhole instabilities during LBW/EBW can be another reason for the formation of pores. In that case, the pores may be suppressed through a suitable adjustment of the welding parameters, i.e., the weld depth to width ratio should be reduced $[69,70]$.

In comparison to single-phase fec HEAs such as $\mathrm{CoCrFeMnNi}$ and $\mathrm{Al}_{x} \mathrm{CoCrFeNi}$ with $x \leq 0.3$, CCAs (mainly $\mathrm{Al}_{x} \mathrm{CoCrCu}_{y} \mathrm{FeNi}$ with $0.3<x \leq 1$ and $\left.0 \leq y \leq 1\right)$ are more challenging to weld due to their complex microstructures consisting of multiple phases. For instance, for low $\mathrm{Al}$ and $\mathrm{Cu}$ contents (e.g., $\mathrm{Al}_{0.6} \mathrm{CoCrFeNi}$ ), as-cast CCAs are polycrystalline with a two-phase matrix (bcc/B2: disordered and ordered body-centered cubic phases interconnected at the nmscale), which contains $\mu \mathrm{m}$-scale disordered fcc regions [71]. With increasing $\mathrm{Al}$ content in $\mathrm{Al}_{x} \mathrm{CoCrFeNi} \mathrm{CCAs}$, the volume fraction of the $\mathrm{B} 2$ phase increases at the expense of the fcc phase that eventually vanishes in as-cast alloys with $x>$ 

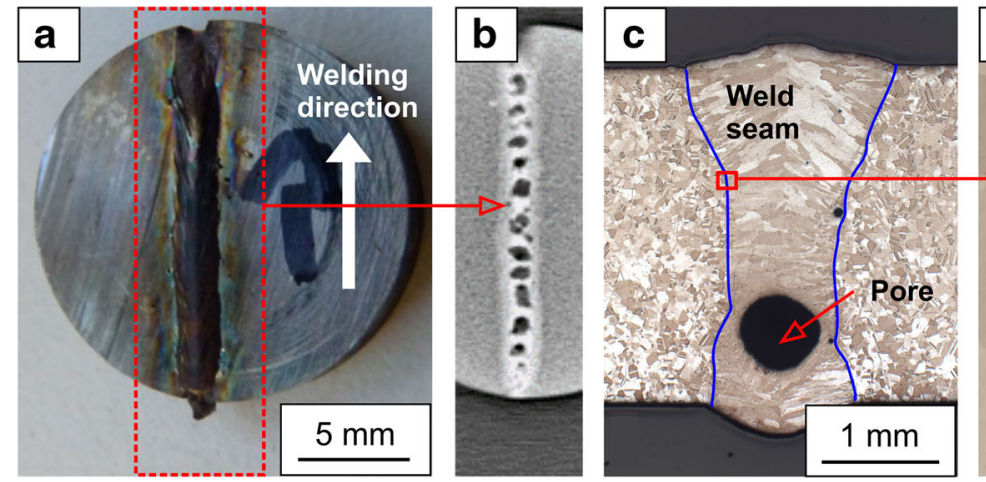

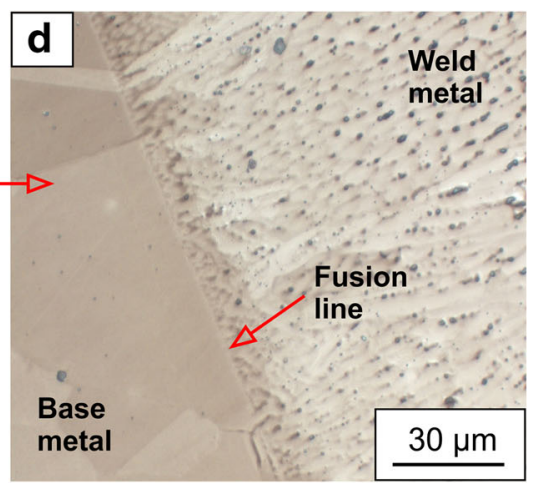

microscopy: cross-section showing the weld seam geometry. d Magnified area showing the fusion line between the base metal and the weld metal
Fig. 5 Weld joint in the equiatomic CoCrFeMnNi HEA. a Photo from the top. b X-ray image from the top showing pores in the weld. c Optical solidification simulations and showed that the AlCoCrCuFeNi CCA in the as-cast condition should exhibit a dendritic microstructure with a large melting range between 300 and $350 \mathrm{~K}$ [40]. The accuracy and correctness of these simulations rely on thermodynamic databases. Even though databases are available for HEAs/ CCAs (e.g., TCHEA4 for the 2020's version of the Thermo-Calc(C) software), several studies reported in the literature on HEAs/CCAs (e.g., summarized in [75]) show that thermodynamic calculations are often relatively inaccurate. In that connection, the solidification simulations of Martin et al. [40] could be revaluated using the (continuously increasing thermodynamic) database of the 2020's version. However, given the increasing number of publications on phase stability (and welding) of HEAs/CCAs, it is assumed that the implementation of these results in Thermo-Calc $($ ) will improve the quality and accuracy of the TCHEA databases in the near future.

Hot cracking (see Figs. 6a, b and 7a) can result in numerous geometrical micro-defects such as notches that act as stress concentrators for secondary overload cracking of brittle phases. This was reported by Nahmany et al. [74] for EBwelded $\mathrm{Al}_{x} \mathrm{CoCrFeNi} \mathrm{CCAs}$ with different Al-contents. The authors showed that the susceptibility to cracking was highest for large Al-contents (e.g., with $x=0.8 \mathrm{wt} . \%$, in accordance with the original figure labeled "P2" in Fig. 8) while alloys
Fig. 6 Hot cracking in the equiatomic $\mathrm{AlCoCrCuFeNi}$ HEA: light optical micrographs of (a) the TIG weld and HAZ, (b) detail of HAZ-cracking due to $\mathrm{Cu}$-segregation in the interdendritic areas. The figures were taken from ref. [40], (C) The Minerals, Metals and Materials Society and ASM International, reprinted with permission of Springer Nature
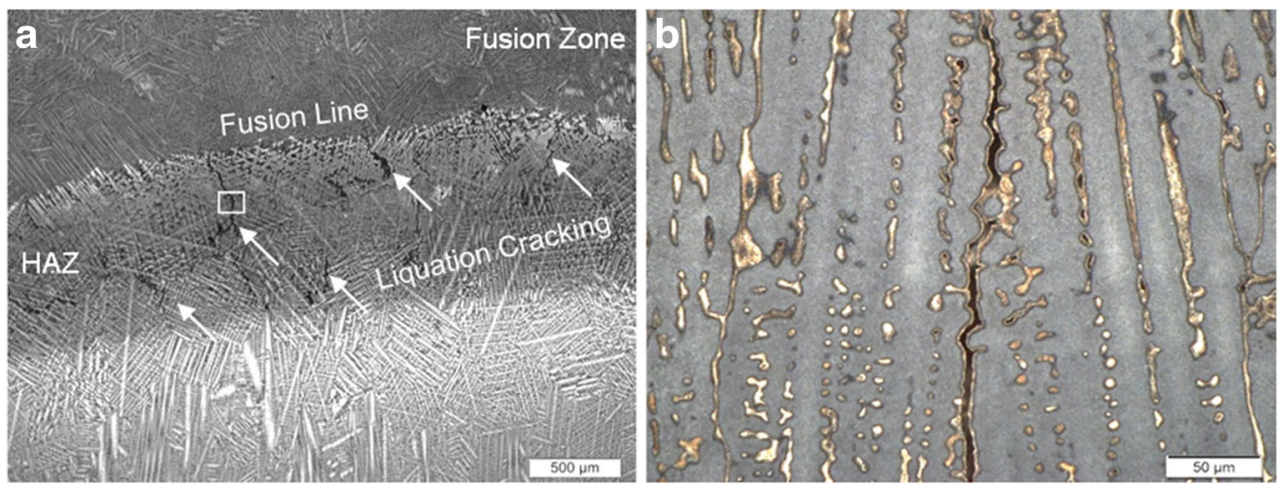
Fig. 7 Different types of cracks: (a) interdendritic hot cracking in a TIG weld of the

$\mathrm{AlCoCrCu}{ }_{0.5} \mathrm{FeNi} \mathrm{CCA}$ and (b) transgranular cold cracking in the $\mathrm{HAZ}$ of the equiatomic $\mathrm{AlCoCrCuFeNi} \mathrm{HEA.} \mathrm{The}$ figures were taken from ref. [40], (C) The Minerals, Metals and Materials Society and ASM International, reprinted with permission of Springer Nature

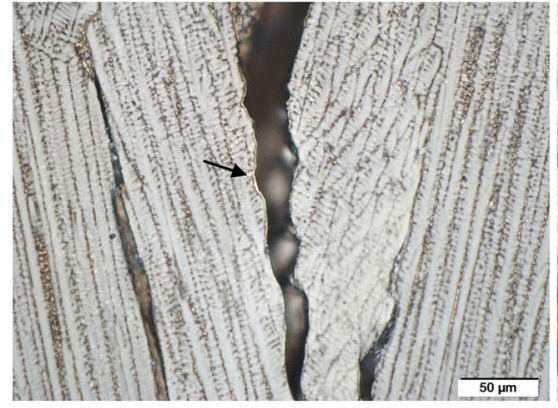

a

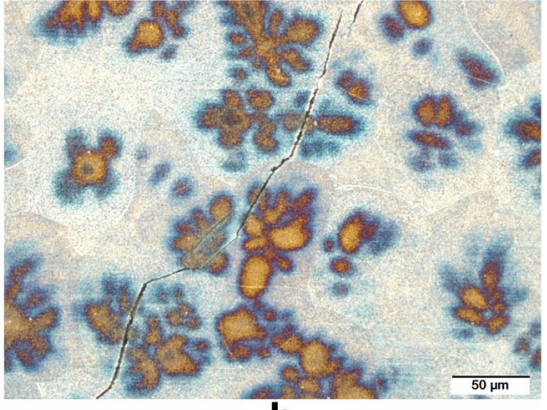

b with lower $\mathrm{Al}$ concentrations did not show any cracks (P3 alloy with $x=0.6 \mathrm{wt} . \%)$.

The reason is that Al stabilizes a hard and brittleordered B2 intermetallic phase whose volume fraction increases as the $\mathrm{Al}$ concentration increases [76]. For this reason, a decrease in $\mathrm{Al}$ content should allow a reduction of the susceptibility to cracking of the $\mathrm{Al}_{x} \mathrm{CoCrFeNi}$ CCAs. Nahmany et al. [74] assumed that (hot) cracking is additionally influenced by residual stresses resulting from fast cooling of the weld metal. To our knowledge, no studies focusing on the determination of residual stresses in HEA/CCA welds have been reported so far, but they would be crucial to qualify HEAs and CCAs for industrial applications.

Martin et al. [40] hypothesized that the hot cracks in the welded $\mathrm{AlCoCrCu}{ }_{0.5} \mathrm{FeNi} \mathrm{CCA}$ (resulting from $\mathrm{Cu}$-segregation, see Fig. 7b) acted as stress concentrators that induced the formation of further cracks. These cracks, which are characterized by brittle transgranular fracture topography (see Fig. 9a, b), may propagate through hard and brittle areas of both the HAZ and the WM. Although the authors of refs. [40, 74] did not consider this possibility, we assume that these cracks can be classified as cold cracks. In contrast to hot cracks, cold cracks appear occasionally after welding has been
Fig. 8 Deep penetration bead-onplate EB-welds on

$\mathrm{Al}_{0.8} \mathrm{CrFeCoNi}$ (P2, right column) and $\mathrm{Al}_{0.6} \mathrm{CrFeCoNi}_{\text {(P3, left }}$ column) with different weld heat inputs. Samples P3-2 and P3-4 (low Al content) exhibit no weld defects whereas P2-1 and P2-3 (high $\mathrm{Al}$ concentration) exhibit distinct weld defects, e.g., hot cracks in the weld joint top region and centerline cracking, see P2-3. The figures were taken from ref. [74], () Springer Science + Business Media New York and ASM International, reprinted with permission of Springer Nature
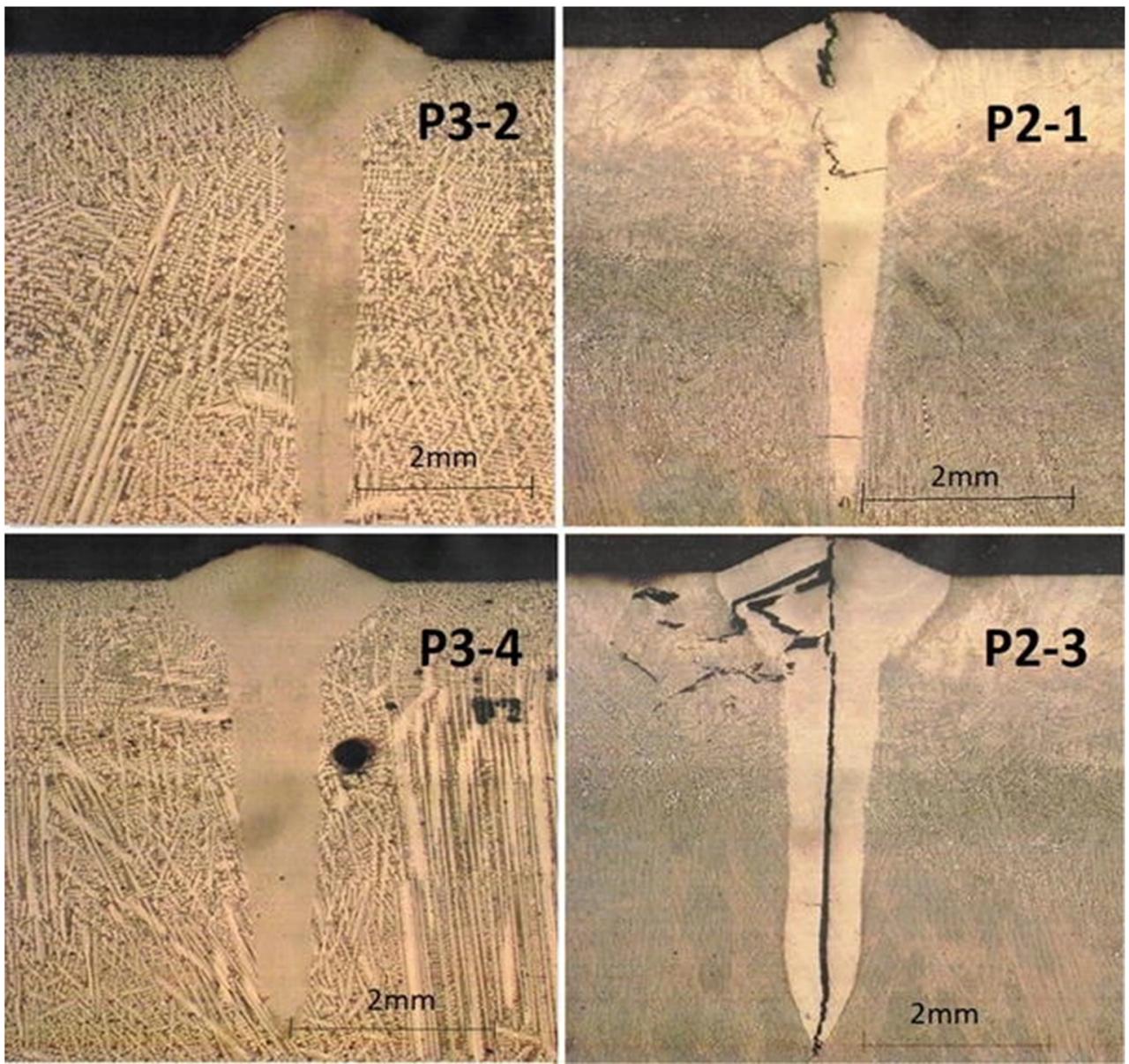
Fig. 9 Topography of fracture surface across the fusion line of the AlCoCrFeNi TIG-welded joint: IG intergranular cracking in dashed line region across the fusion line, TG transgranular cracking in the HAZ and fusion zone. The figures were taken from ref. [40], () The Minerals, Metals and Materials Society and ASM International, reprinted with permission of Springer Nature
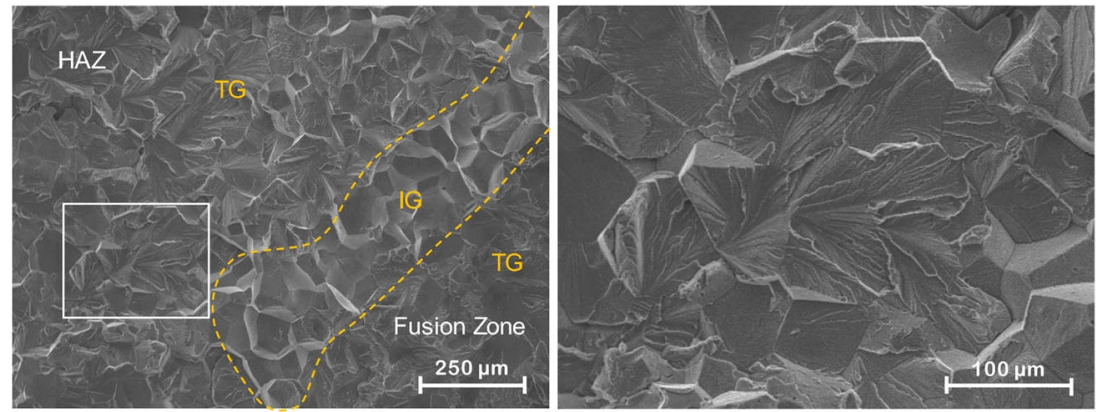

completed, i.e., way below the solidus temperature of the alloy. For this reason, hot and cold cracks show distinct fracture topographies. Hot cracks in weld joints are typically characterized by their interdendritic cracking pathways (see transgranular fracture in Fig. 7a), but they can also show an intergranular behavior with rather smooth fracture surfaces, i.e., less deformation capability at high temperatures [77]. In contrast, the transgranular quasi cleavage facets in Figs. 7b and $9 \mathrm{~b}$ suggest a certain ability for deformation, i.e., crack propagation after welding at lower temperatures, and thus indicate cold cracking. It must be emphasized that further work is needed to confirm that the cracks observed in Figs. $7 \mathrm{~b}$ and $9 \mathrm{~b}$ are really cold cracks. This example demonstrates some of the challenges that may occur during (fusion) welding processing of HEAs.

In view of the emerging field of hydrogen generation, transportation, and use, the fcc CoCrFeMnNi HEA and its medium-entropy derivatives are assumed to be promising materials for storage vessel wall materials for liquid hydrogen and high-pressure purposes. There are several reasons for this. First, these alloys show outstanding mechanical properties at cryogenic temperatures (tensile strength, toughness, and fatigue resistance) $[15,16,42,52]$. Second, some alloys of this family have a significant hydrogen solubility ( $>70 \mathrm{wt}$.-ppm) $[78,79]$ that is comparable or even superior [80] to austenitic stainless steels [81]. Third, it was partially proven in ref. [82] that the fcc $\mathrm{CoCrFeMnNi}$ has a hydrogen-assisted cracking (HAC) resistance that is comparable to that of $304 \mathrm{~L}$ austenitic stainless steels. However, from the available literature, it is unclear whether hydrogen is involved in terms of delayed HAC in HEA welds. This is therefore an area where further research is required to advance the field.

\subsubsection{Dissimilar welds (fusion welding)}

Only a small number of welding studies are available for dissimilar welds: (1) TIG welding of $\mathrm{Al}_{0.1} \mathrm{CoCrFeNi}$ fec HEAs to conventional AISI304 [52] and (2) LBW of dissimilar material processing (as-cast vs. rolled material) conditions of fcc HEA CoCrFeMnNi [42]. The mechanical joint properties were characterized by tensile tests. Intermixing of the two alloys was found to result in an increase of the yield and tensile strengths of the HEA-WM compared to the HEA$\mathrm{BM}$, even though the strain to fracture was significantly reduced and all samples fractured in the HEA-BM. This indicates that fcc HEAs have the potential for DMWs with austenitic steels as fcc HEA-types have similar thermophysical properties compared to austenitic steels (see Table 2). The knowledge of the thermophysical properties (like the thermal expansion coefficient) can be useful for estimating the possible weld distortions. This is important if HEAs are used as structural materials in terms of external restraints of the weld joint.

As the CoCrFeMnNi HEA has outstanding mechanical properties at cryogenic temperatures $[15,16]$, it is a candidate material to replace austenitic stainless steels $304 \mathrm{~L}$ or $316 \mathrm{~L}$ in safety-relevant components where superior cryogenic properties are essential. Due to its high relatively high costs, associated to the large amounts of $\mathrm{Co}$ and $\mathrm{Ni}$, the $\mathrm{CoCrFeMnNi}$ HEA will have to be joined to conventional materials to reduce the costs, and further investigations of the weldability of DMWs involving HEAs are still required.

\subsubsection{Solid-state friction stir welding}

In current FSW-studies, single-phase HEAs are being considered, e.g., $\mathrm{Al}_{0.1} \mathrm{CoCrFeNi}$ [83-85] and $\mathrm{CoCrFeMnNi} \mathrm{HEAs}$ $[47,53,54,86,87]$. The quaternary CoCrFeNi MEA $[88,89]$ is also of interest. The weldability as a material property is hard to express quantitatively. According to the definition of weldability in the ISO-recommendation [90], a material can be welded if the technique ensures the integrity of the metal by a corresponding technological process in such a way that the welded parts meet the technical requirements. For this reason, all the above-mentioned alloys have qualitatively good weldability by FSW, for example by avoidance of further process steps like preheating or PWHT of the weld joint.

The advantage of FSW compared to fusion welding processes is that the process temperature is below the solidus temperature, which decreases the susceptibility to form brittle IMCs. For example, in Al-to-steel joints, thick layers of hard and brittle IMCs are present after fusion welding while their volume fraction can be significantly reduced when FSW is used instead of fusion welding [91, 92]. Similar beneficial 
effects of FSW may be anticipated in HEAs/CCAs. The formation of IMCs is a complex process and depends on the temperature and the underlying percentage mixture of the involved materials.

Despite the good weldability of HEAs and MEAs, FSWspecific weld defects (see Fig. 10) such as tunnel defects, contamination of the stirring zone by intermetallic particles due to tool wear, or insufficient penetration of the welded parts may be present. However, these defects can be avoided by adjusting the welding parameters. Most FSW joints in HEAs and MEAs show the formation of so-called "white band defects." These are areas of extreme local deformation and act as barriers to the accumulation of finely dispersed tool material particles such as WC (see Fig. 10 FSW joints show a significantly increased hardness in the area of the stirring zone [86] with a reduced strain to fracture (see Fig. 4). Possible cold cracks or overload cracks can originate from the FSWspecific defects and thus reduce the ductility of the FSW-joint.

Regarding the current state of the art, the integrity of the FSW-joint in HEAs and MEAs seems to be more influenced by the tool material and the welding parameters than by the material itself (see Fig. 10). This is due to the strong deformation that results from possible embedded WC particles by the abrasive tool wear. In case of significant degradation of the weld joint's mechanical properties, the integrity of a component would be reduced. Particularly in case of FSW, proper welding parameters and adequate tools, considering both their geometry and their material, should be determined in advance. Thus, from today's perspective, it is premature to draw any conclusions from the limited amount of FSW studies on HEA/ CCA systems.

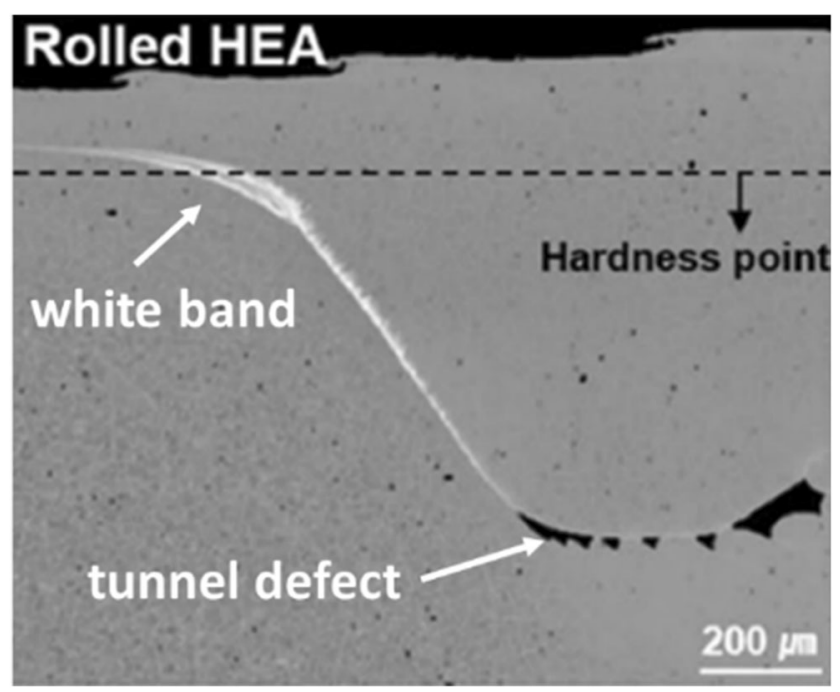

Fig. 10 White band and tunnel defects in a FSW joint of a cold-rolled $\mathrm{Co}_{16} \mathrm{Cr}_{28} \mathrm{Fe}_{28} \mathrm{Ni}_{28}$ MEA. The figure was taken and adapted (insertion of the white arrows and defect denotation) from ref. [86], (C) The Korean Institute of Metals and Materials, reprinted with permission of Springer Nature

\section{Summary and outlook}

Only limited attention has been paid to the weldability of HEAs/CCAs, and the current state of the art allows us to state the following conclusions:

- Several techniques were reported to produce reliable metallurgical bonding using HEAs/ CCAs. Both fusion welding (such as TIG, LBW, EBW) and solid-state processes (like FSW) have been successfully applied.

- The equiatomic fcc and single-phase CoCrFeMnNi alloy is currently the most studied HEA in terms of the different welding techniques and parameters, its mechanical properties, and microstructural evolution during welding. Since its introduction, new HEA systems such as bcc refractory HEAs (e.g., HfNbTaTiZr) were discovered. However, the welding properties of these alloys are still relatively unknown. Generally, possible effects like grain refinement, elemental segregations, and secondary phase precipitation must be anticipated during welding of HEAs. For that reason, the welding influence on possible application properties such as corrosion resistance must be further investigated to bring HEAs/CCAs to potential technical uses.

- For welding techniques with high energy input, i.e., EBW and LBW, loss of elements with low melting temperature and high vapor pressure will become a challenge for controlling the chemical composition (especially in the case of EBW due to the necessary vacuum during welding). For further fusion welding techniques like MIG, the development of suitable welding filler materials will be a challenge. The problem is that the nearly equiatomic composition must be guaranteed. It must be clarified how a certain HEA/CCA-system must be processed. Further effects like the possible burn-off loss of chemical elements must be identified and compensated by the filler metal. Nonetheless, some HEA systems with low melting points were already used as filler metals for soldering.

- The welding experiments are currently limited to singlelayer welding. Studies on detailed residual stress distributions during welding and weld parameter effect on weld seam geometries and possible distortion effects are missing. This was caused by the limited amount of materials in the past (typically within gram-range). Meanwhile, higher amounts of these materials can be manufactured. Hence, the number of publications on welding residual stresses will increase considering different welding processes and loading conditions. Such studies are essential for the intended use of these alloys as structural materials. Besides, guidelines for effective preheat scenarios, as well as PWHT procedures, must be developed to ensure the integrity of the weld seam. This is also a challenge for dissimilar metal welds. 
- HEAs/CCAs offer nearly limitless possibilities for tuning properties, which make them attractive for future applications. The understanding of the material behavior, especially for the CoCrFeMnNi HEA, which has been the focus of most studies, is already well developed in comparison to the understanding of processing. As a result, the welding experience is mostly still in its early stages, and systematic studies on the welding of HEAs/CCAs are necessary to fully elucidate their application potentials.

Abbreviations CCA, Compositionally complex alloy; EB(W), Electron beam (welding); FSW, Friction stir welding; HAZ, Heat affected zone; HEA, High-entropy alloy; HV, Vickers hardness; IMC, Intermetallic compound; LB(W), Laser beam (welding); MEA, Medium-entropy alloy; PWHT, Post weld heat treatment; TIG, Tungsten inert gas; WM, Weld metal

Acknowledgements This study was a part of the research project "SURDIA - Surface Degradation Phenomena and Utilization of Innovative Alloy Systems" at Bundesanstalt für Materialforschung und -prüfung (BAM), Berlin, Germany. Mr. Marco Lammers (Division 9.3, BAM) is thanked for the laser welding experiment.

Funding Open Access funding enabled and organized by Projekt DEAL. Guillaume Laplanche received funding from the German Research Foundation (DFG) through project 3607/3-2 of the priority program SPP 2006.

Open Access This article is licensed under a Creative Commons Attribution 4.0 International License, which permits use, sharing, adaptation, distribution and reproduction in any medium or format, as long as you give appropriate credit to the original author(s) and the source, provide a link to the Creative Commons licence, and indicate if changes were made. The images or other third party material in this article are included in the article's Creative Commons licence, unless indicated otherwise in a credit line to the material. If material is not included in the article's Creative Commons licence and your intended use is not permitted by statutory regulation or exceeds the permitted use, you will need to obtain permission directly from the copyright holder. To view a copy of this licence, visit http://creativecommons.org/licenses/by/4.0/.

\section{References}

1. Miracle DB, Senkov ON (2017) A critical review of high entropy alloys and related concepts. Acta Mater 122:448-511. https://doi. org/10.1016/j.actamat.2016.08.081

2. Tsai MH, Yeh JW (2014) High-entropy alloys: a critical review. Mater Res Lett 2(3):107-123. https://doi.org/10.1080/21663831. 2014.912690

3. Cantor B, Chang ITH, Knight P, Vincent AJB (2004) Microstructural development in equiatomic multicomponent alloys. Mater Sci Eng A 375-377:213-218. https://doi.org/10.1016/ j.msea.2003.10.257

4. Grote KH, Antonson EK (2009) Springer Handbook of Mechanical Engineering. Springer, Berlin/Heidelberg

5. Starke EA Jr, Staley JT (1996) Application of modern aluminum alloys to aircraft. Prog Aerosp Sci 32(2/3):131-172. https://doi.org/ 10.1016/0376-0421(95)00004-6
6. Otto F, Dlouhy A, Somsen C, Bei H, Eggeler G, George EP The influences of temperature and microstructure on the tensile properties of a CoCrFeMnNi high-entropy alloy. Acta Mater 61(15): 5743-5755. https://doi.org/10.1016/j.actamat.2013.06.018

7. Li Z, Tasan CC, Pradeepa KG, Raabe D (2017) A TRIP-assisted dual-phase high-entropy alloy: grain size and phase fraction effects on deformation behavior. Acta Mater 131:323-335. https://doi.org/ 10.1016/j.actamat.2017.03.069

8. He JY, Wang H, Huang HL, Xu XD, Chen MW, Wu Y, Liu XJ, Nieh TG, An K, Lu ZP (2016) A precipitation-hardened high-entropy alloy with outstanding tensile properties. Acta Mater 102: 187-196. https://doi.org/10.1016/j.actamat.2015.08.076

9. Yifan Y, Wang Q, Lu J, Liu CT, Yang Y (2015) High-entropy alloy: challenges and prospects. Mater Today 19(6):349-362. https://doi.org/10.1016/j.mattod.2015.11.026

10. Yao MJ, Pradeep KG, Tasan CC, Raabe D (2014) A novel, single phase, non-equiatomic $\mathrm{FeMnNiCoCr}$ high-entropy alloy with exceptional phase stability and tensile ductility. Scr Mater 72(73):5-8. https://doi.org/10.1016/j.scriptamat.2013.09.030

11. Manzoni A, Glatzel U (2020) High-entropy alloys: balancing strength and ductility at room temperature. In: Flemings MC (ed) Buschow KHJ. Encyclopedia of Materials, Science and Technology. https://doi.org/10.1016/B978-0-12-803581-8. 11774-6

12. Senkov ON, Wilks GB, Miracle DB, Chuang CP, Liaw PK (2010) Refractory high-entropy alloys. Intermetallics 18(9):1758-1765. https://doi.org/10.1016/j.intermet.2010.05.014

13. Laplanche G, Volkert UF, Eggeler G, George EP (2016) Oxidation behavior of the CrMnFeCoNi high-entropy alloy. Oxid Met 85(56):629-645. https://doi.org/10.1007/s11085-016-9616-1

14. Schneider M, George EP, Manescau TJ, Zalezak T, Hunfeld J, Dlouhy A, Eggeler G, Laplanche G (2020) Analysis of strengthening due to grain boundaries and annealing twin boundaries in the CrCoNi medium-entropy alloy. Int J Plast 124:155-169. https://doi. org/10.1016/j.ijplas.2019.08.009

15. Thurston KVS, Gludovatz B, Yu Q, Laplanche G, George EP, Ritchie RP (2019) Temperature and load-ratio dependent fatigue-crack growth in the $\mathrm{CrMnFeCoNi}$ high-entropy alloy. J Alloys Compd 794:525-533. https://doi.org/10.1016/j. jallcom.2019.04.234

16. Gludovatz B, Hohenwarter A, Catoor D, Chang EH, George EP, Ritchie RO (2014) A fracture-resistant high-entropy alloy for cryogenic applications. Sci 345(6201):1153-1158. https://doi.org/10. 1126/science. 125458

17. Kulkarni R, Murty BS, Srinivas V (2018) Study of microstructure and magnetic properties of $\mathrm{AlNiCo}(\mathrm{CuFe})$ high entropy alloy. J Alloys Compd 746:194-199. https://doi.org/10.1016/j.jallcom. 2018.02.275

18. Gao MC, Yeh JW, Liaw PK, Zhang Y (2016) High-entropy alloys, fundamentals and applications. Springer International Publishing, Cham. https://doi.org/10.1007/978-3-319-27013-5

19. Miracle DB (2017) High-entropy alloys: a current evaluation of founding ideas and core effects and exploring nonlinear alloys. JOM 69:2130-2136. https://doi.org/10.1007/s11837-017-2527-z

20. Senkov ON, Wilks GB, Scott JM, Miracle DB (2011) Mechanical properties of $\mathrm{Nb}_{25} \mathrm{Mo}_{25} \mathrm{Ta}_{25} \mathrm{~W}_{25}$ and $\mathrm{V}_{20} \mathrm{Nb}_{20} \mathrm{Mo}_{20} \mathrm{Ta}_{20} \mathrm{~W}_{20}$ refratory high entropy alloys. Intermetallics 19(5):698-706. https://doi.org/10.1016/j.intermet.2011.01.004

21. Tsai KY, Tsai MH, Yeh YW (2013) Sluggish diffusion in Co-CrFe-Mn-Ni high-entropy alloys. Acta Mater 61(13):4887-4897. https://doi.org/10.1016/j.actamat.2013.04.058

22. Durand A, Peng L, Laplanche G, Morris JR, George EP, Eggeler G (2020) Interdiffusion in Cr-Fe-Co-Ni medium-entropy alloys. Intermetallics 122:106789. https://doi.org/10.1016/j.intermet. 2020.106789 
23. Laplanche G, Berglund S, Reinhart C, Kostka A, Fox F, George EP (2018) Phase stability and kinetics of $\sigma$-phase precipitation in CrMnFeCoNi high-entropy alloys. Acta Mater 161:338-351. https://doi.org/10.1016/j.actamat.2018.09.040

24. Laplanche G (2020) Growth kinetics of $\sigma$-phase precipitates and underlying diffusion processes in $\mathrm{CrMnFeCoNi}$ high-entropy alloys. Acta Mater 199:193-208. https://doi.org/10.1016/j.actamat. 2020.08.023

25. Fan Y, Li P, Chen K, Fu L, Shan A, Chen Z (2020) Effect of fiber laser welding on solute segregation and proprieties of $\mathrm{CoCrCuFeNi}$ high entropy alloy. J Laser Appl 32:022005. https://doi.org/10. 2351/1.5128535

26. Zhang Y, Zuo TT, Tang Z, Gao MC, Dahmen KA, Liaw PK, Lu ZP (2014) Microstructures and properties of high-entropy alloys. Prog Mater Sci 61:1-93. https://doi.org/10.1016/j.pmatsci.2013.10.001

27. Kumar A, Gupta M (2016) An insight into evolution of light weight high entropy alloys: a review. Metals 6:199. https://doi.org/10. 3390/met6090199

28. Diao H, Feng R, Dahmen K, Liaw P (2017) Fundamental deformation behavior in high-entropy alloys: an overview. Curr Opin Mater Sci 21:252-266. https://doi.org/10.1016/j.cossms.2017.08.003

29. Stenberg T, Barsoum Z, Astrand E, Ericson-Öberg A, Schneider C, Hedegard J (2017) Quality control and assurance in fabrication of welded structures subjected to fatigue loading. Weld World 61: 1003-1015. https://doi.org/10.1007/s40194-017-0490-5

30. ISO 5817:2014 Welding - Fusion-welded joints in steel, nickel, titanium and their alloys (beam welding excluded) - Quality levels for imperfections. International Standardization Organization (ISO), 3rd ed., February, 2014

31. Chen S, Tong Y, Liaw P (2018) Additive manufacturing of highentropy alloys: a review. Entropy-Switz 20:937. https://doi.org/10. 3390/e20120937

32. Guo J, Tang C, Rothwell G, Li L, Wang YC, Yang Q, Ren X (2019) Welding of high entropy alloys - a review. Entropy-Switz 21:431448. https://doi.org/10.3390/e21040431

33. Garcia Filho FC, Monteiro SN (2020) Welding joints in high entropy alloys: a short-review on recent trends. Mater 13:1411. https:// doi.org/10.3390/ma13061411

34. Lopes JG, Oliveira JP (2020) A short review on welding and joining of high entropy alloys. Metals 10(2):212. https://doi.org/10. 3390/met10020212

35. Arab A, Guo Y, Zhou Q, Chen P (2020) Joining AlCoCrFeNi high entropy alloys and Al-6061 by explosive welding method. Vacuum 174:109221. https://doi.org/10.1016/j.vacuum.2020.109221

36. Lei Y, Hu SP, Yang TL, Song XG, Luo Y, Wang GD (2020) Vacuum diffusion bonding of high-entropy A10.85CoCrFeNi alloy to TiAl intermetallic. J Mater Process Technol 278:116455. https:// doi.org/10.1016/j.jmatprotec.2019.116455

37. Panina E, Yurchenko N, Zherebtsov S, Stepanov N, Salishchev G, Ventzke V, Dinse R, Kashaev N (2019) Laser beam welding of a low density refractory high entropy alloy. Metals 9:1351. https:// doi.org/10.3390/met9121351

38. Yeh JW, Chen SK, Lin SJ, Gan JY, Chin TS, Shun TT, Tsau CH, Chang SY (2004) Nanostructured High-entropy alloys with multiple principal elements: novel alloy design concepts and outcomes. Adv Eng Mater 6(5):299-303. https://doi.org/10.1002/adem. 200300578

39. Martin AC, Fink C (2019) Initial weldability study on A10.5CrCoCu0.1FeNi high-entropy alloy. Weld World 63:739750. https://doi.org/10.1007/s40194-019-00702-7

40. Martin AC, Oliveira JP, Fink C (2020) Elemental effects on weld cracking susceptibility in AlxCoCrCuyFeNi high-entropy alloy. Metall Mater Trans A 51A:778-787. https://doi.org/10.1007/ s11661-019-05564-8

41. Nam H, Park C, Kim C, Kim H (2018) Effect of post weld heat treatment on weldability of high entropy alloy welds. Sci Technol
Weld Join 23(5):420-427. https://doi.org/10.1080/13621718.2017. 1405564

42. Nam H, Park S, Chun EJ, Kim H, Na Y, Kang N (2020) Laser dissimilar weldability of cast and rolled $\mathrm{CoCrFeMnNi}$ highentropy alloys for cryogenic applications. Sci Technol Weld Join 25(2):127-134. https://doi.org/10.1080/13621718.2019.1644471

43. Luo D, Xiao Y, Hardwick L, Snell R, Way M, Morell XS, Livera F, Ludford N, Panwisawas C, Dong H, Goodall R (2021) High entropy alloys as filler metals for joining. Entropy 23(1):78. https://doi. org/10.3390/e23010078

44. Voiculescu I, Geanta V, Vasile IM, Stefanoiu R, Tonoiu M (2013) Characterisation of weld deposits using as filler metal a high entropy alloy. J Optoelectron Adv Mater 15(7):650-654

45. Wu Z, David SA, Leonard DN, Feng Z, Bei H (2018) Microstructures and mechanical properties of a welded CoCrFeMnNi high-entropy alloy. Sci Technol Weld Join 23(7): 585-595. https://doi.org/10.1080/13621718.2018.1430114

46. Laurent-Brocq M, Akhatova A, Perriere L, Chebini S, Sauvage X, Leroy E, Champion Y (2015) Insights into the phase diagram of the CrMnFeCoNi high entropy alloy. Acta Mater 88:355-365. https:// doi.org/10.1016/j.actamat.2015.01.068

47. Jo MG, Kim HJ, Kang M (2018) Microstructure and mechanical properties of friction stir welded and laser welded high entropy alloy CrMnFeCoNi. Met Mater Int 24(1):73-83. https://doi.org/ 10.1007/s12540-017-7248-x

48. Oliveira JP, Curado TM, Zeng Z, Lopes JG, Rossinyol E, Park JM, Schell N, Braz Ferandes FM, Kim HS (2020) Gas tungsten arc welding of as-rolled CrMnFeCoNi high entropy alloy. Mater Design 189:108505. https://doi.org/10.1016/j.matdes.2020.108505

49. Wu Z, David SA, Feng Z, Bei H (2016) Weldability of a high entropy CrMnFeCoNi alloy. Scr Mater 124:81-85. https://doi.org/ 10.1016/j.scriptamat.2016.06.046

50. Chen Z, Wang B, Duan B, Zhang X (2019) Mechanical properties and microstructure of laser welded FeCoNiCrMn high entropy alloy. Mater Lett 262:127060. https://doi.org/10.1016/j.matlet.2019. 127060

51. He X, DebRoy T, Fuerschbach PW (2003) Alloying element vaporization during laser spot welding of stainless steel. J Phys D Appl Phys 36:3079. https://doi.org/10.1088/0022-3727/36/23/033

52. Nam H, Park S, Park N (2020) Weldability of cast CoCrFeMnNi high-entropy alloys using various filler metals for cryogenic applications. J Alloys Compd 819:153278. https://doi.org/10.1016/j. jallcom.2019.153278

53. Park S, Park C, Na Y, Kim HS, Kang N (2018) Effects of (W, Cr) carbide on grain refinement and mechanical properties for CoCrFeMnNi high entropy alloys. J Alloys Compd 770:222-228. https://doi.org/10.1016/j.jallcom.2018.08.115

54. Zherebsov S, Stephanov N, Shysultanov D et al (2018) Use of novel welding technologies for high-entropy alloys joining. Mater Sci Forum 941:919-924. https://doi.org/10.4028/www.scientific. net/MSF.941.919

55. Kashaev N, Ventzke V, Petrov N, Horstmann M, Zherebtsov S, Shaysultanov D, Sanin V, Stepanov N (2019) Fatigue behaviour of a laser beam welded CoCrFeNiMn-type high entropy alloy. Mater Sci Eng A 766:138358. https://doi.org/10.1016/j.msea. 2019.138358

56. Böllinghaus T, Herold H, Cross CE, Lippold JC (2008) Hot cracking phenomena in welds II. Springer, Berlin/ Heidelberg

57. Laplanche G, Gadaud P, Horst O, Otto F, Eggeler G, George EP (2015) Temperature dependencies of the elastic moduli and thermal expansion coefficient of an equiatomic, singlephase $\mathrm{CoCrFeMnNi}$ high-entropy alloy. J Alloys Compd 625:348-353. https://doi.org/ 10.1016/j.jallcom.2014.11.061

58. Chen BR, Yeh AC, Yeh JW (2016) Effect of one-step recrystallization on the grain boundary evolution of $\mathrm{CoCrFeMnNi}$ high 
entropy alloy and its subsystems. Sci Rep 6:22306. https://doi.org/ 10.1038/srep22306

59. Chou HP, Chang YS, Chen SK, Yeh JW (2009) Microstructure, thermophysical and electrical properties in AlxCoCrFeNi $(0 \leq x \leq 2)$ high-entropy alloys. Mater Sci Eng B 163:184-189. https://doi.org/ 10.1016/j.mseb.2009.05.024

60. Guo T, Li J, Wang J, Wang WY, Liu Y, Luo X, Kou H, Beaugnon E (2018) Microstructure and properties of bulk Al0.5CoCrFeNi high-entropy alloy by cold rolling and subsequent annealing. Mater Sci Eng A 729:141-148. https://doi.org/10.1016/j.msea. 2018.05.054

61. Zhou PF, Xiao DH, Wu Z, Song M (2019) Microstructure and mechanical properties of $\mathrm{AlCoCrFeNi}$ high entropy alloys produced by spark plasma sintering. Mater Res Express 6:0865e7. https://doi.org/10.1088/2053-1591/ab2517

62. Jin K, Sales BC, Stocks GM, Samolyuk GD, Daene M, Weber WJ, Zhang Y, Bei H (2016) Tailoring the physical properties of Nibased single-phase equiatomic alloys by modifying the chemical complexity. Sci Rep 6:20159. https://doi.org/10.1038/srep20159

63. Wegst C, Wegst M, (2010) Stahlschlüssel Taschenbuch, Verlag Stahlschlüssel Wegst GmbH, Marbach, 22 edition

64. Brandes EA (1992)(eds) Smithells Metals Reference Book, Butterworth-Heinemann, Oxford, 7 edition

65. Munitz A, Salhov S, Hayun S, Frage N (2016) Heat treatment impacts the micro-structure and mechanical properties of AlCoCrFeNi high entropy alloy. J Alloys Compd 683:221-230. https://doi.org/10.1016/j.jallcom.2016.05.034

66. Legatt RH (2008) Residual stresses in welded structures. Int J Pres Ves Pip Doi 85:155-151. https://doi.org/10.1016/j.ijpvp. 2007.10.004

67. Schroepfer D, Kromm A, Kannengiesser T (2017) Engineering approach to assess residual stresses in welded components. Weld World 61:91-106. https://doi.org/10.1007/s40194-016-0394-9

68. Schroepfer D, Kromm A, Kannengiesser T (2018) Formation of multi-axial welding stresses due to material behaviour during fabrication of high-strength steel components. Weld World 63:43-51. https://doi.org/10.1007/s40194-018-0650-2

69. Huang LJ, Hua XM, Wu DS, Li F (2018) Numerical study of keyhole instability and porosity formation mechanism in laser welding of aluminum alloy and steel. J Mater Process Technol 252:421-431 S0924013617304600

70. Alizadeh-Sh M, Marashi SPH, Ranjbarnodeh E, Razavi S, Oliveira JP (2020) Prediction of solidification cracking by an empiricalstatistical analysis for laser cladding of Inconel 718 powder on a non-weldable substrate. J Opt Las Tec 128:106244 S0030399219323515

71. Wang WR, Wang WL, Wang SC, Tsai YC, Lai CH, Yeh YW (2012) Effects of $\mathrm{Al}$ addition on the microstructure and mechanical property of $\mathrm{AlxCoCrFeNi}$ high-entropy alloys. Intermetallics 26 : 44-51. https://doi.org/10.1016/j.intermet.2012.03.005

72. Borkar T, Gwalani B, Choudhuri D, Mikler CV, Yannetta CJ, Chen X, Ramanujan RV, Styles MJ, Gibson MA, Banerjee R (2016) A combinatorial assessment of AlxCrCuFeNi2 $(0<\mathrm{x}<1.5)$ complex concentrated alloys: microstructure, microhardness, and magnetic properties. Acta Mater 116:63-76. https://doi.org/10.1016/j. actamat.2016.06.025

73. Tong CJ, Chen YL, Yeh JW, Lin SJ, Chen SK, Shun TT, Tsau CH, Chang SY (2005) Microstructure characterization of $\mathrm{AlxCoCrCuFeNi}$ high-entropy alloy system with multiprincipal elements. Metall Mater Trans A 36:881-893. https://doi.org/10.1007/ s11661-005-0283-0
74. Nahmany M, Hooper Z, Stern A, Geanta V, Voiculescu I (2016) AlxCrFeCoNi high-entropy alloys: surface modification by electron beam bead-on-plate melting. Metallogr Microstruct Anal 5: 229-240. https://doi.org/10.1007/s13632-016-0276-y

75. Saal JE, Berglund IS, Sebastian JT, Kiaw PK, Olson GB (2018) Equilibrium high entropy alloy phase stability from experiments and thermodynamic modeling. Scr Mater 146:5-8. https://doi.org/ 10.1016/j.scriptamat.2017.10.027

76. Asabre A, Kostka A, Stryzhyboroda O, Pfetzing-Micklich J, Hecht U, Laplanche G (2019) Effect of Al, Ti and C additions on Widmanstätten microstructures and mechanical properties of cast A10.6CoCrFeNi compositionally complex alloys. Mater Des 184: 108201. https://doi.org/10.1016/j.matdes.2019.108201

77. Kannengiesser T, Boellinghaus T (2014) Hot cracking tests - an overview of present technologies and applications. Weld World 58:397-421. https://doi.org/10.1007/s40194-014-0126-y

78. Rhode M, Wetzel A, Ozcan O, Nietzke J, Richter T, Schroepfer D (2020) Hydrogen diffusion and local Volta potential in high- and medium entropy alloys. Symposium on Materials and Joining Technology, Magdeburg, Germany, September 2020. IOP Conf Ser: Mater Sci Eng 882:012015. https://doi.org/10.1088/1757899X/882/1/012015

79. Zhao Y, Park JM, Lee DH, Song EJ, Suh JY, Ramamurty U, Jang JI (2019) Influences of hydrogen charging method on the hydrogen distribution and nanomechanical properties of face-centered cubic high-entropy alloy: a comparative study. Scr Mater 168:76-80. https://doi.org/10.1016/j.scriptamat.2019.04.025

80. Sahlberg M, Karlsson D, Zlotea C, Jansson U (2016) Superior hydrogen storage in high entropy alloys. Sci Rep 6:36770. https:// doi.org/10.1038/srep36770

81. Caskey GR, Sisson RD (1981) Hydrogen solubility in austentic steels. Scr Mater 15(11):1187-1190. https://doi.org/10.1016/00369748(81)90295-7

82. Ichii K, Koyama M, Tasan CC, Tsuzaki K (2018) Comparative study of hydrogen embrittlement in stable and metastable highentropy alloys. Scr Mater 150(5):74-77. https://doi.org/10.1016/j. scriptamat.2018.03.003

83. Komarasamy M, Kumar N, Tang Z, Mishra RS, Liaw PK (2015) Effect of microstructure on the deformation mechanism of friction stir-processed A10.1CoCrFeNi high entropy alloy. Mater Res Lett 3(1):30-34. https://doi.org/10.1080/21663831.2014.958586

84. Kumar N, Komarasamy M, Nelaturu P, Tang Z, Liaw PK, Mishra RS (2015) Friction stir processing of a high entropy alloy Al0.1CoCrFeNi. JOM 67:5-1013. https://doi.org/10.1007/s11837015-1385-9

85. Wang T, Shukla S, Komarrasamy M, Liu K, Mishra RS (2019) Towards heterogeneous AlxCoCrFeNi high entropy alloy via friction stir processing. Mater Lett 236:472-475. https://doi.org/10. 1016/j.matlet.2018.10.161

86. Park S, Nam H, Na Y, Kim H, Moon Y, Kang N (2020) Effect of initial grain size on friction stir weldability for rolled and cast CoCrFeMnNi high-entropy alloys. Met Mater Int 26:641-649. https://doi.org/10.1007/s12540-019-00466-1

87. Xu N, Song Q, Bao Y (2019) Microstructure evolution and mechanical properties of friction stir welded $\mathrm{FeCrNiCoMn}$ highentropy alloy. Mater Sci Tech-Lond 35:5-584. https://doi.org/10. $1080 / 02670836.2019 .1573525$

88. Zhu ZG, Sun YF, Ng FL, Goh MH, Liaw PK, Fujii H, Nguyen QB, $\mathrm{Xu}$ Y, Shek CH, Nai SML, Wei J (2018) Friction-stir welding of a ductile high entropy alloy: microstructural evolution and weld 
strength. Mater Sci Eng A 711:524-532. https://doi.org/10.1016/j. msea.2017.11.058

89. Qin X, Xu Y, Sun Y, Fujii H, Zhu Z, Shek CH (2020) Effect of process parameters on microstructure and mechanical properties of friction stir welded CoCrFeNi high entropy alloy. Mater Sci Eng A 782:139277. https://doi.org/10.1016/j.msea.2020.139277

90. ISO/TR 581:2005 Weldability - Metallic materials - General principles. International Standardization Organization (ISO), 1st ed., February, 2005

91. Atabaki MM, Nikodinovski M, Chenier P, Ma J, Harooni M, Kovacevic R (2014) Welding of aluminum alloys to steel: an overview. J Manuf Sci Prod 14(2):59-78. https://doi.org/10.1515/ jmsp-2014-0007

92. Tanaka T, Nezu M, Uchida S, Hirata T (2020) Mechanism of intermetallic compound formation during the dissimilar friction stir welding of aluminum and steel. J Mater Sci 55:3064-3072. https:// doi.org/10.1007/s10853-019-04106-2

Publisher's note Springer Nature remains neutral with regard to jurisdictional claims in published maps and institutional affiliations. 